\title{
Caminhos e descaminhos da macrometrópole paulista: dinâmica econômica, condicionantes externos e perspectivas
}

\author{
Paths and detours of the São Paulo Macrometropolis: \\ economic dynamics, external determinants and perspectives
}

Alexandre Abdal [I]

Caio César Ferreira de Macedo [II] Gabriel Almeida Antunes Rossini [III] Ricardo Carlos Gaspar [IV]

\section{Resumo}

0 presente artigo aborda aspectos econômicos relevantes do aglomerado urbano que constitui a Macrometrópole Paulista (MMP). Primeiramente, identificamos as principais dinâmicas associadas à globalização e as suas manifestações em São Paulo. Em seguida, discutimos o acidentado percurso do desenvolvimento brasileiro nas últimas décadas, com ênfase nas pressões que pesam sobre a indústria nacional, o que significa caracterizar o contexto mais geral no qual a MMP está inscrita. Posteriormente, situamos a MMP na trajetória recente da economia brasileira e analisamos o seu desempenho industrial com os decorrentes impactos territoriais. Concluímos avaliando a economia paulista em face dos desafios contemporâneos, salientando o papel do Estado nacional na implementação de políticas regionais capazes de estimular um desenvolvimento mais equilibrado no conjunto do território do País.

Palavras-chave: Macrometrópole Paulista; Região Metropolitana de São Paulo; indústria; desindustrialização.

\begin{abstract}
The present article discusses relevant economic aspects of the urban agglomerate that constitutes the so-called Macrometrópole Paulista - MMP (São Paulo Macrometropolis). First, we identify the main dynamics associated with globalization and its manifestations in São Paulo. Then, we analyze the problematic route of Brazilian growth in the last decades emphasizing pressures on the national industry, which means we characterize the more general context where the MMP is inserted. Subsequently, we situate the MMP in the recent trajectory of the Brazilian economy and analyze its industrial performance and the consequent territorial impacts. Finally, the concluding remarks evaluate São Paulo's economy in view of contemporary challenges, highlighting the national State's role of implementing regional policies in order to stimulate a more balanced territorial development in the whole country.
\end{abstract}

Keywords: São Paulo Macrometropolis (MMP); Metropolitan Region of São Paulo; industry; deindustrialization. 


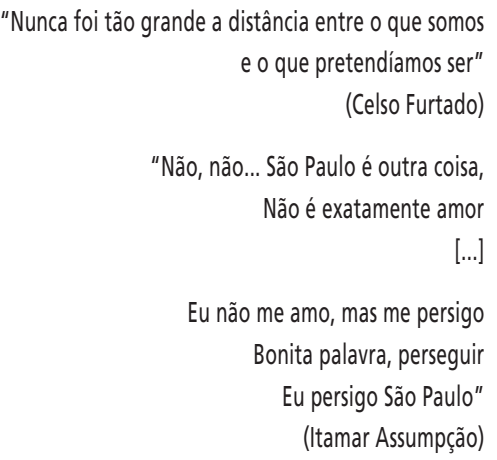

\section{Introdução}

A contínua regionalização das grandes urbanizações contemporâneas acompanha as profundas mudanças da economia mundial, sobrepondo, quando não substituindo, o papel industrial originário das cidades pelo aprofundamento de suas características terciárias. Em um contexto de economia aberta, cada vez mais, as cidades competem entre si, em todo o mundo, pela atração de investimentos públicos e privados, capitais e trabalhadores qualificados. Muitas delas têm logrado êxito nesse mister, absorvendo parcela significativa de excedentes financeiros na forma de capital de risco, de investimento imobiliário-financeiro, de inversões puramente especulativas e, até, aquelas provenientes de origem ilícita.

A metrópole de São Paulo é um bom exemplo das tendências atuais da economia globalizada e de seus impactos em urbanidades compactas, historicamente constituídas em função da indústria nos países em desenvolvimento. Mais precisamente, em São Paulo se observa uma profunda reestruturação da economia urbana, reconfigurada e relocalizada majoritariamente no espaço regional do entorno ao município de São Paulo e de seus limites metropolitanos originários. Constitui uma nova espacialidade urbana, conectada aos processos de reestruturação produtiva, à disseminação das tecnologias de informação e comunicação e à hegemonia do capital financeiro e de suas interações com 0 capital imobiliário.

Não obstante, é preciso sublinhar que o contexto mais geral sob o qual tais mudanças na economia da metrópole paulista acontecem é o da reestruturação da indústria brasileira. 0 parque industrial sofre, já há alguns anos, os efeitos prejudiciais da sobrevalorização cambial e dos juros altos, ao mesmo tempo que é desafiado pelo acirramento da competição internacional, com o consequente aumento das importações e um insuficiente dinamismo na incorporação de inovações e de novas tecnologias. 0 presente artigo não desconsidera esse pano de fundo e reconhece que tal situação exerce uma influência duradoura e negativa sobre a configuração produtiva regional e nacional. Ou seja, é nesse contexto adverso, de pressões sobre a indústria nacional, que as regiões brasileiras estão sendo inseridas nas tendências atuais da economia global. 
Com a adoção das premissas anteriores como tela de fundo, este texto aborda aspectos econômicos e políticos relevantes derivados da nova morfologia do grande aglomerado urbano que constitui a Macrometrópole Paulista (MMP), cuja configuração atual adquiriu expressão a partir do último quartel do século passado. Após esta introdução, na próxima seção identificamos algumas das principais dinâmicas metropolitanas associadas à globalização e a suas manifestações em São Paulo. Na seção terceira, discutimos o acidentado percurso do desenvolvimento nacional nas últimas décadas, com ênfase nas dificuldades e nas pressões que pesam sobre a indústria brasileira, o que implica caracterizar o contexto no qual a MMP está inscrita. Na quarta seção, situamos a MMP na trajetória recente da economia brasileira e, a partir da mobilização de evidência empírica, analisamos o seu desempenho, com especial atenção para a divisão espacial de trabalho entre as suas componentes: Município de São Paulo (MSP), Anel Metropolitano e Entorno Macrometropolitano. Finalmente, nas considerações finais, analisamos mais de perto as novas determinações que se desenham para a indústria paulista em face dos impasses e dos desafios da sociedade brasileira no final da segunda década do século XXI.

\section{Metrópoles brasileiras e globalização: o caso de São Paulo}

No Brasil, como no mundo, o fenômeno da agregação territorial de amplos espaços urbanos extrapola os limites das antigas delimitações metropolitanas, provoca o transbordamento da periferia pobre e agrava a segregação socioespacial. Em especial, a metrópole de São Paulo assistiu a uma transformação acelerada de seu tradicional status econômico-industrial na direção de uma polaridade não somente econômica, mas marcadamente política, administrativa e cultural. Seu crescimento vertiginoso, ao longo do século $X X$, resultado da intensa acumulação fordista (em seguida ao auge do café) que caracterizou boa parte do período, traduziu-se nos planos urbanísticos e viários das décadas de 1930 e 1940. E, depois, na implantação da indústria automobilística, na segunda metade da década seguinte. Ambos representaram decisivos pontos de inflexão na trajetória da RMSP rumo à liderança na industrialização do País.

Contudo, a capital paulista, desde os anos 1990, consolidou-se como centro prestador de sofisticados serviços corporativos e financeiros, sobrepondo novas funções às funções anteriores (Diniz e Diniz, 2004; Comin et al., 2012). 0 estado de São Paulo caracteriza-se precisamente pela presença do mais amplo e complexo sistema de cidades do Brasil, conformando-se em seu território uma intensa rede de articulações funcionais, nucleada pelo espaço de fluxos e relações que se estabelece no entorno da RMSP (IBGE, 2008). Esse espaço, denominado Macrometrópole Paulista (MMP), é composto pelas três metrópoles do Estado com dinâmica efetivamente metropolitana (Observatório das Metrópoles, 2009): São Paulo, Campinas e Baixada Santista, e por aglomerações urbanas, como São José dos Campos, Sorocaba e Jundiaí, situadas em um raio aproximado de $200 \mathrm{~km}$ ao redor da capital. Fortemente polarizadas pela capital paulista, a MMP congrega os centros 
Figura 1 - A Macrometrópole Paulista

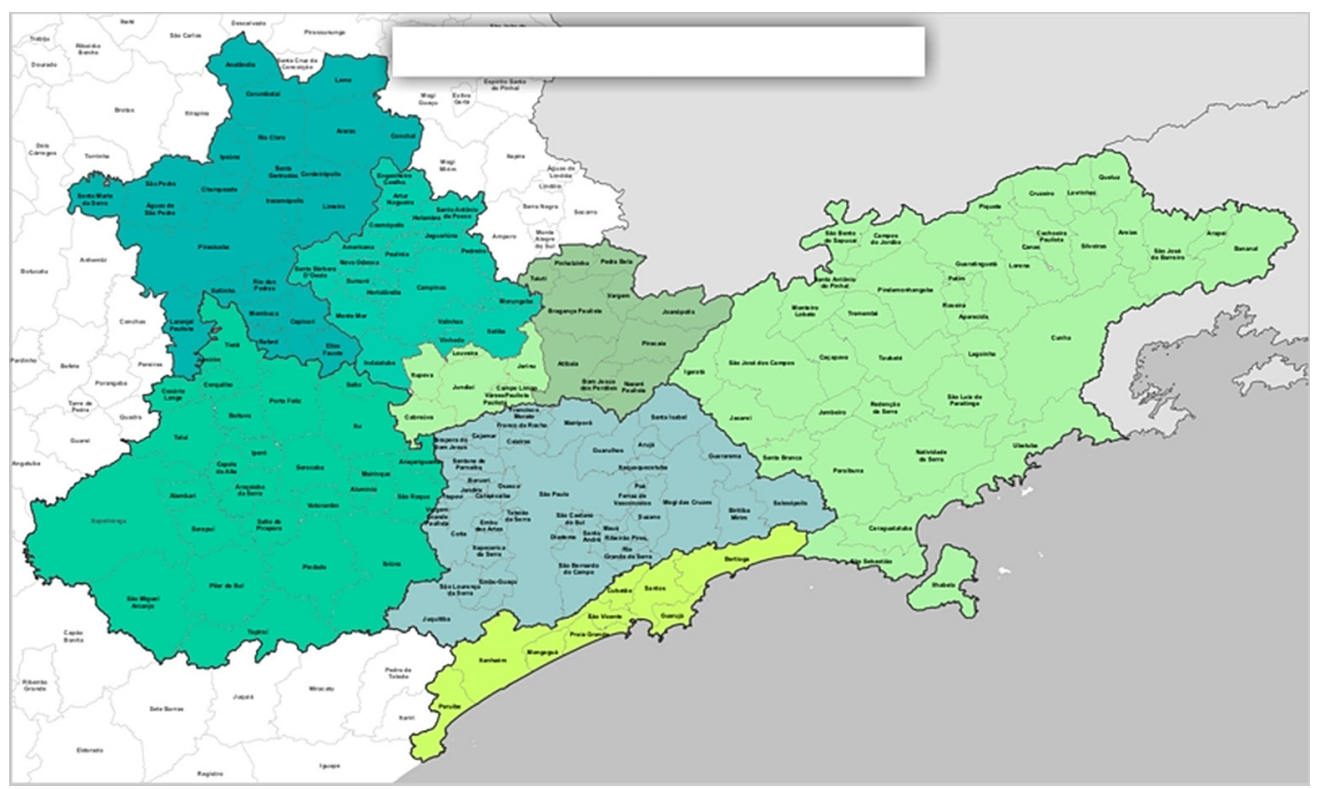

Fonte: Emplasa (Disponível em: https://www.emplasa.sp.gov.br/MMP). Acesso em: 17 set 2018.

urbanos que mais se beneficiaram da desconcentração produtiva e populacional da RMSP (Seade e Emplasa, 2011; Lencioni, 2011).

0 espaço regional ampliado da MMP referencia parcela importante dos processos geoeconômicos em curso, desencadeados a partir do município de São Paulo. A MMP constitui, assim, o polo hegemônico de uma rede urbana estadual, nacional e subcontinental, que multiplica centros regionais subsidiários, dotados de crescentes atributos econômicos, sociais e culturais em áreas nas quais a metrópole dominante não mais possui condições de capitalizar para si. Esse espaço urbanizado constitui uma área de enorme importância estratégica. Nele, estão superpostas realidades distintas, que se distanciam da espacialização eminentemente industrial que caracterizava a RMSP até os anos 1980, e concentram agudas contradições. As metrópoles contemporâneas são poderosos entroncamentos de redes múltiplas, policêntricas, transfronteiriças, de caráter difuso, articuladas e integradas ao redor de certos polos hegemônicos (Mattos, 2008; Gaspar, 2009 e 2011).

As cidades-regiões globais constituídas são marcadas por aspectos distintivos quanto a organização social, estrutura espacial interna e ambiente construído (Scott, 2012). Contudo, a direção central do movimento de urbanização é hegemonizada pelo setor financeiro e pelas atividades a ele agregadas no 
conjunto do sistema econômico. Tal fenômeno, por sua vez, está correlacionado à desregulação geral, à concentração da renda e ao consumo de luxo que lhe é inerente, bem como à informalidade e à precarização das atividades produtivas de baixo valor agregado. Trata-se do conjunto de atividades de gestão do capital, que envolve tarefas materiais e simbólicas, cujo epicentro, no Brasil, está na municipalidade de São Paulo. Do ponto de vista regional, é nesse contexto de integração internacional, cuja contrapartida foi a retração das políticas regionais orientadas para diminuição das desigualdades territoriais, que uma crescente competição entre cidades por investimentos públicos e privados, capitais e mão de obra qualificada se impôs (Brenner, 2004; Markusen e Schrock, 2006).

Além do componente financeiro e das políticas recessivas aplicadas pelo governo brasileiro nos anos 1980 e 1990, a recente trajetória da MMP reflete a opção das empresas tecnologicamente mais avançadas, com maior coeficiente de agregação de valor, de fortalecer a concentração de empregos e da produção nas regiões sul e sudeste do Brasil. Referimo-nos a indústrias, intensivas em capital, de material elétrico e de comunicações, de material de transporte, química e de informática, entre outras. Para elas, o que conta é a proximidade dos mercados consumidores, 0 acesso à melhor infraestrutura e à mais alta qualificação da mão de obra, por isso a preferência da maioria por localizar-se nas cercanias da capital paulista. Isso serve também para o setor de serviços, sobretudo para os segmentos de serviços especializados e que lidam mais intensamente com o conhecimento e o comércio atacadista.
Já os empreendimentos produtivos mais tradicionais, trabalho-intensivos e/ou muito dependentes de custos, como a indústria têxtil, de alimentos e de calçados, percorreram o caminho inverso, de desconcentração produtiva, rumo a outras regiões do estado ou do País. 0 evidente processo de terciarização de São Paulo (também presente em outras metrópoles mundiais, associado ao processo de financeirização do desenvolvimento urbano) não pode aqui ser tomado como sinônimo simples de desindustrialização, pois, no segmento de serviços, os de natureza empresarial ligados à esfera produtiva adquirem importância decisiva. 0 crescimento do terciário avançado na capital paulista está associado, em alguma medida, à base industrial dos entornos metropolitano e macrometropolitano e aos vínculos que a economia de conhecimento estabelece com a chamada economia real (Comin e Amitrano, 2003).

São novos nexos empresariais dependentes de fluxos de informação produzidos nos núcleos (lugares) mais avançados do sistema. A desconcentração industrial relativa ocorrida nas últimas décadas no Brasil e que causou forte impacto à RMSP seguiu um padrão hierárquico fundado no grau de inovação e dinamismo. Isto é, "quanto mais moderna e dinâmica a atividade em questão, maior sua probabilidade de permanecer - ou mesmo se reconcentrar na região correspondente à Macrometrópole Paulista" (Abdal, 2009, p. 55). A integração da indústria com os serviços e o mencionado reforço, em São Paulo, de um terciário avançado, suporte da estrutura de controle econômico exercido a partir metrópole paulistana, seguem a mesma direção. Tais reforço e ampliação da concentração desse terciário avançado configuram a interpretação da cidade de São Paulo 
como buraco negro de serviços especializados (Abdal et al., 2014).

Agora, o contexto mais geral no qual ocorrem os processos de desconcentração produtiva e de formação e consolidação da MMP é um contexto de reestruturação da indústria brasileira. Embora ele não seja determinante da dinâmica econômica que toma forma na MMP, condiciona as possibilidades e os limites dessa região, industrialmente intensiva e diversificada. Vejamos, então, os rumos e os descaminhos da indústria nacional para, depois, investigarmos, mais de perto, as características e as tendências produtivas da MMP.

\section{Trajetória recente da economia brasileira: crise e desindustrialização}

A dinâmica do nexo existente entre o setor industrial e o desenvolvimento econômico ocupa parte relevante das discussões das ciências sociais, no limite, desde o advento da manufatura moderna. Os resultados dessas investigações afirmam que a alocação dos recursos produtivos entre os diferentes setores econômicos de um país, pertencentes ao centro do sistema, passa por modificações conforme o país se desenvolve e incrementa a sua renda per capita. Assim, após certo desenvolvimento, verifica-se a tendência de aumento da participação das atividades industriais e contração relativa da agricultura. Essa alteração resulta da mudança do padrão de consumo das famílias, decorrente de alterações no seu nível de renda, o que redireciona os investimentos produtivos, aumentando a capacidade de produção e aperfeiçoando as forças produtivas. Esse processo acaba por promover o seguinte encadeamento: (1) rendimentos crescentes de escala; (2) estímulos à procura de manufaturados (em virtude da baixa dos preços); (3) aumento da eficiência marginal do capital; e (4) novas inversões na indústria, ocasionando uma estrutura produtiva mais diversificada (Marconi e Rocha, 2011).

Tregenna (2009 e 2011) reformulou e ampliou a concepção tradicional de desindustrialização. Com as suas formulações, a desindustrialização passou também a ser entendida como procedente da redução tanto do emprego industrial quanto do valor adicionado pela indústria, como proporção do emprego total e do PIB, respectivamente. Desse ponto de vista, não há desindustrialização quando a produção industrial está em declínio ou sem dinamismo, mas, sim, quando a indústria diminui a sua importância no provimento de empregos e/ou de valor adicionado.

Tendo as formulações anteriores em vista, recuperamos parte dos contornos mais marcantes da trajetória recente da indústria brasileira. Julgamos necessário resgatar o curso do nosso desenvolvimento industrial para restaurar o fio corrente da história e abordar, dessa perspectiva, os problemas crescentes enfrentados pela indústria brasileira, ou seja, o contexto mais amplo no qual a trajetória recente da MMP se insere.

A indústria torna-se preponderante no Brasil quando se processou, ao longo da década de 1930, o que Furtado (2009[1959]) chamou de "deslocamento do centro dinâmico" da economia brasileira. Com o "deslocamento", a dinâmica do mercado interno, e não mais a atividade agroexportadora, passou a determinar a trajetória dos investimentos da economia. 
Para além da industrialização restringida ocorrida entre o governo Dutra e o segundo governo Vargas (1945 e 1955), ${ }^{1}$ ao longo, sobretudo, da segunda metade da década de 1950, teve lugar a instalação de indústrias, como a automobilística, de construção naval, de material elétrico pesado e de outras indústrias mecânicas de bens de capital. Outrossim, expandiram-se as indústrias básicas (siderúrgica, petrolífera, metalúrgica dos não ferrosos, celulose e papel, química pesada) (Tavares, 1963). A partir dos anos 1950, o capital dos países desenvolvidos encontrou, na economia brasileira (assim como em proporções diferentes no restante da América Latina), o mercado que começava a escassear no mundo desenvolvido. 0 País passou, então, a figurar como destino do deslocamento espacial do capital do centro, engendrando um processo de acumulação que, a despeito de ser determinado a partir de dentro, tinha os seus setores mais dinâmicos conduzidos pelos imperativos do capital de fora.

A partir de 1974, com o II Plano Nacional de Desenvolvimento (II PND), as prioridades mudaram. Esse Plano buscou enfrentar a crise internacional da época sem levar o País à recessão. Para tanto, direcionou investimentos para setores considerados chave. A estratégia de 1974 completa e integra a estrutura industrial brasileira, possibilitando, ao País - a despeito da dependência tecnológica -, acessar os elementos que pautaram a II Revolução Industrial. Ao final da década de 1970, o Brasil tinha uma indústria de transformação cujo produto representava cerca de 33\% do PIB (Cano, 2012). Ademais, a elevação da oferta e o crescimento em "marcha forçada", porque sustentado por investimentos públicos via estatais, apareciam como solução para o Brasil se tornar a potência média com que os militares sonhavam (Tavares et al., 2007).

Ao longo dos anos 1980, a maior parte do acréscimo de capacidade produtiva provém da maturação das inversões decorrentes do II PND, o que provocou importantes aumentos de oferta em um cenário no qual o setor externo novamente enfrentava severas restrições. $A$ década de 1980 representou período de crise e indefinições associadas ao passivo acumulado pelo setor público, notadamente o endividamento externo ocorrido após 1964. Ademais, havia um rápido, forte e sustentado processo inflacionário (Lopes, 1985).

Diante desse cenário, optou-se pela implementação de políticas heterodoxas que almejavam maior estabilidade de preços, em detrimento à usual recessão decorrente da receita ortodoxa de estabilização. As consequências desse período para a indústria brasileira foram severas e resultaram em um desempenho atípico no âmbito da sua tendência de crescimento de longo prazo e em um movimento contrário ao do avanço industrial experimentado pelos países do centro do sistema e, principalmente, pelos países de industrialização mais recente da Ásia. Entre 1980 e 1990, a produção industrial caiu cerca de $2 \%$.

Ao mesmo tempo, o setor de serviços ampliou-se a uma taxa média anual de 2,8\%, revelando desempenho mais próspero que 0 da indústria (Bonelli e Gonçalves, 1998). Como resultado, o hiato tecnológico, que havia sido atenuado pela estratégia de 1974, voltou a aumentar. Mesmo o parque produtivo industrial brasileiro tendo passado pela "década perdida", mantendo uma estrutura relativamente complexa e integrada, chega ao fim da década de 1980 defasado quanto às tecnologias de 
processo e de produto e, sobretudo, de organização da produção (Kupfer, 2003).

A década de 1990 foi distinguida pela liberalização econômica, pela estabilização dos preços, pelo crescente movimento de financeirização que incorporou o Brasil à economia internacional como plataforma internacional de valorização financeira e pelas consequências das sucessivas crises externas (México em 1993, Ásia em 1997 e Rússia em 1998). As reformas liberalizantes, implementadas desde a presidência de Collor, buscaram (1) a redução escalonada das barreiras não tarifárias e do imposto de importação (pilares da proteção da indústria nacional); (2) a abertura da conta de capital; (3) a internacionalização do mercado brasileiro de títulos; (4) as subvenções tributárias a donos de ações e a ganhos financeiros de não residentes; (5) as modificações legais que buscaram resguardar os credores do Estado (Lei da Responsabilidade Fiscal); e (6) a privatização das estatais relevantes nas áreas da petroquímica e siderurgia, segmentos que concentravam mais de $90 \%$ da presença do Estado como produtor direto (Bielschowsky, 1998) e também das estatais que ofertavam serviços de utilidade pública (transporte coletivo, energia elétrica, gás, telefone).

Essa nova realidade, combinada com a recessão decorrente da política de estabilização então promovida, fez com que as empresas, de uma forma geral, implementassem, ao longo dos anos iniciais da década de 1990, certo ajuste defensivo que promoveu ampla "destruição não criadora" (Tavares, 1999) caracterizada pelo enxugamento de custos, por meio de demissões, importação de insumos e terceirização de atividades. No momento seguinte, o quadro macroeconômico decorrente do Plano Real (1994) impediu a promoção de ciclos consistentes de investimento em novas plantas produtivas, produziu baixo crescimento médio do PIB (o crescimento anual médio dos anos 1990 foi de 2,85\% a.a.) e um novo cenário competitivo para a indústria nacional, tornando o padrão da crise do desenvolvimentismo o padrão dos anos 1990. 0 parque produtivo brasileiro passou a enfrentar um ambiente pautado por câmbio valorizado, taxas de juros muito elevadas e redução das barreiras à entrada de empresas estrangeiras (Carvalho e Kupfer, 2008).

Ferraz et al. (2004), após analisarem as consequências da desregulamentação sobre a composição e a produtividade da indústria brasileira, consideraram que a indústria nacional se adaptou diferenciadamente à condução da política econômica dos anos 1990. 0 parque industrial doméstico tornou-se mais competitivo em algumas frentes, menos em função de melhorias tecnológicas do que da renovação seletiva de equipamentos e processos produtivos defasados, do aumento das importações de insumos e bens intermediários e da descontinuidade da produção de certos bens de maior sofisticação tecnológica. Além disso, houve retração das atividades de pesquisa e desenvolvimento $(P \& D)$, largo distanciamento da relação produto-emprego e certa especialização regressiva no padrão de comércio exterior, com aumento do peso de produtos mais simples nas exportações (calçados, couros, peles e açúcar) e de maior sofisticação nas importações (equipamentos eletrônicos, indústrias diversas e material elétrico) (Kupfer, 2003).

Outras consequências desse período foram ressaltadas por Marquetti (2002) e Bonelli (2005). Marquetti chamou a atenção para a 
ocorrência de desindustrialização em virtude da menor participação do emprego industrial no emprego total e da diminuição do valor adicionado pela indústria no PIB, resultados dos baixos investimentos realizados, sobretudo na indústria de transformação, durante as décadas de 1980 e 1990. A desindustrialização afetou, segundo o autor, negativamente a habilidade de crescimento da economia brasileira, pois estaria associada à passagem de recursos e de trabalho da indústria para setores de menor produtividade, o que tende a proporcionar, no longo prazo, menor crescimento do produto.

Bonelli, por seu turno, verificou que a participação da indústria no PIB, a custo de fatores (sem tributos e subsídios), caiu significativos 11 pontos percentuais entre 1985 e 1995 (de $42,3 \%$ para $31,4 \%$ ), principalmente em função da diminuição da contribuição da indústria de transformação no PIB (de 31,6\% para $20,6 \%$ ). Segundo o autor, a perda da participação da indústria no PIB foi motivada pelo processo de liberalização da economia brasileira. ${ }^{2}$

0 início do primeiro governo Lula (2002) marca a manutenção da política macroeconômica herdada do governo FHC II (1999-2002), não obstante a suspensão do veto anteriormente existente à política industrial. ${ }^{3}$ Houve, assim, a manutenção do tripé organizado em torno de uma política monetária condicionada pelas metas de inflação, câmbio flutuante e política fiscal orientada para a obtenção de superávits primários. Os críticos ${ }^{4}$ enfatizavam que esse arranjo macroeconômico era inconciliável com políticas industriais e de transferência de renda capazes de propiciar a retomada do crescimento econômico e o dinamismo industrial (Morais e Saad Filho, 2011). Mantinha-se, assim, a integração subordinada da economia brasileira à internacional.

Para diversos analistas, a consequência desses movimentos (manutenção de política macroeconômica adversa em meio à inserção internacionalmente subordinada) significou processo de desindustrialização $0^{5}$ e reprimarização da pauta de exportações. A reprimarização das exportações é o outro lado da atual forma de vínculo da economia brasileira à rede mundial de acumulação. Possibilitando elevados ganhos em moeda forte, o País absorve reiteradamente poupança externa e, assim, pode conviver com déficits em transações correntes que crescem continuamente (Paulani, 2012; Biancarelli, Rosa e Vergnhanini, 2018).

Contudo, é a desindustrialização uma consequência natural do estágio de desenvolvimento da economia brasileira? Ou é fruto das opções de políticas macroeconômicas e das transformações de inserção internacional da economia brasileira? Aproximamo-nos das formulações que argumentam em favor da relevância do desenho e implementação das políticas macroeconômicas e das transformações da estrutura produtiva global para a desindustrialização. Reconhecemos que tais explicações são diversas e matizadas e, a seguir, destacamos alguns elementos que consideramos mais relevantes para a finalidade do presente artigo. ${ }^{6}$

1) A ampla abertura da economia brasileira, iniciada em 1989 e aprofundada por Collor e FHC, reduziu severamente o grau de proteção do parque produtivo nacional ante os competidores internacionais. As consequências desse processo são centrais para as discussões sobre desindustrialização, por exemplo, dentre os autores denominados 
novos desenvolvimentistas: Bresser-Pereira (2008 e 2012) e Oreiro e Feijó (2010). Tal grupo enfatiza que a abertura econômica e a ampla disponibilidade de certos recursos nos países periféricos resultam vantagens ricardianas que, aliadas aos afluxos recorrentes de capitais externos e a políticas cambiais condicionadas pela preservação de salários reais elevados, impedem a continuidade e a formação de indústrias que poderiam operar e serem bem-sucedidas utilizando tecnologias e processos de gestão no estado da arte. No caso do Brasil, a abertura e a liberalização da economia aliada ao ciclo de valorização dos preços das commodities teriam reforçado a discrepância entre o que esses autores chamam de taxa de câmbio de equilíbrio e a taxa de câmbio de equilíbrio industrial, causando a chamada "doença holandesa", cuja gravidade depende da diferença entre as duas taxas de câmbio de equilíbrio mencionadas.

2) A partir da implementação do Plano Real e das reformas liberalizantes, o câmbio sobrevalorizado, como já indicado, passou a desempenhar papel central para a promoção de maior estabilidade dos preços. Para tanto, houve, ao longo dos últimos 25 anos, a prática de juros reais elevadíssimos e de rigidez dos gastos públicos. Além de as taxas de juros elevadas afetarem negativamente 0 investimento, por conduzirem partes crescentes do capital-dinheiro para a esfera financeira em virtude da sua recorrente maior rentabilidade, contribuem para encurtar o horizonte temporal dos agentes econômicos. A rentabilidade de curto prazo passa a ser privilegiada em detrimento dos investimentos de prazo mais longo, colocando, portanto, ainda mais empecilhos ao investimento produtivo e ao dinamismo industrial (Guttmann, 2008; Chesnais, 2016).

3) 0 deslocamento do centro do eixo da produção mundial para o Leste Asiático, em geral, e para a China, em particular, implicou uma importante reorganização da economia mundial dos anos 1990 em diante (Arrighi, 2008). Embora positivas, nesse processo, as perspectivas para a economia brasileira não foram livres de ambiguidades: por um lado e em que pese o problema apontado acima da dissociação entre a taxa de câmbio de equilíbrio e a taxa de câmbio de equilíbrio industrial, a economia brasileira foi beneficiada pelo boom das commodities. Por outro lado, o crescente ativismo chinês na exportação de manufaturados de cada vez maior valor agregado pressionou a indústria brasileira, em movimento que se intensificou no pós-crise de 2008, com a retração dos mercados dos países desenvolvidos (Barbosa, 2011).

0 resultado agregado desses três elementos (câmbio, juros e pressão competitiva) é um diagnóstico de desindustrialização, caracterizado por uma indústria crescentemente pressionada, com movimentos de perda de dinamismo, retração dos investimentos e empregos, quebra de encadeamentos e esvaziamento de elos. Não é preciso dizer que justamente os territórios dotados de parque industrial mais moderno e dinâmico, MMP a frente, vão sentir mais intensamente tais efeitos.

Vamos, agora, retomar a discussão a respeito da MMP. 


\section{Tendências recentes da Macrometrópole Paulista}

Doravante, vamos situar a MMP na trajetória recente de desenvolvimento brasileiro, discutida na seção anterior, ou seja, fazer interagir dois debates que nem sempre andam ou andaram juntos: o debate sobre a desindustrialização da economia nacional e o debate sobre a desconcentração da produção industrial no Brasil. A seguir, mobilizamos evidência a respeito da trajetória recente da MMP. Importa destacar a performance econômico-produtiva dessa região, bem como caracterizá-la internamente, em termos de divisão espacial do trabaIho produtivo.

A emergência da MMP enquanto território economicamente integrado e portador de lógica espacial própria, inclusive com padrão específico de divisão espacial do trabalho (Abdal, 2009), é fenômeno de jurisdição do amplo e já tradicional debate sobre a desconcentração da produção industrial no Brasil. Os seus determinantes mais longínquos estariam associados aos efeitos do II PND sobre a estrutura industrial da metrópole paulista, a partir de meados dos anos 1970, em dinâmica segundo a qual o esforço de completude de uma matriz industrial de feição fordista, integral e integrada, esteve associada ao movimento de integração do mercado nacional sob a liderança de São Paulo (Diniz, 1993; Cano, 1998). Destacamos, portanto, que, nesse momento, industrialização (busca de alteração da posição da economia nacional na divisão internacional do trabalho) e integração do mercado nacional (estrutura produtiva espacialmente integrada e solidária) foram dois lados de uma mesma moeda.

Já a desindustrialização é fenômeno que remete aos desafios e pressões colocados àquela matriz industrial previamente constituída pelas mudanças na estratégia de desenvolvimento nacional, cujo ponto culminante foi o conjunto das reformas econômicas da passagem dos anos 1980 para os anos 1990. Tal qual discutimos na seção anterior, o tipo de inserção externa emergente foi uma estratégia de integração subordinada à economia internacional, a qual valorizava setores e atividade capazes de vinculação às dinâmicas dos mercados globais. Dadas as dificuldades competitivas da indústria brasileira, desde a rapidez e extensão da abertura até a sua dificuldade crônica em incorporar progresso técnico e inovar, chegando aos desafios impostos pela ascensão chinesa, o resultado é uma indústria pressionada, com elos e encadeamentos cada vez mais enfraquecidos e segmentos esvaziados, incapaz de internalizar os possíveis benefícios advindos do ciclo de crescimento do início dos anos 2000. Nem a retomada parcial de políticas industriais de corte vertical entre 2003 e 2014 foi capaz de alterar tal quadro.

Do ponto de vista regional, o saldo da nova inserção externa da economia brasileira foi, como defendeu Pacheco (1998), a fragmentação da nação (enfraquecimento e/ou quebra daqueles encadeamentos e solidariedade inter e intrarregionais constituídos a partir de 1930 e consolidados ao longo da década de 1970 e início da de 1980). Importante notar que essa quebra de encadeamentos e laços de solidariedade inter e intrarregional se faz em momento de dificuldades da indústria nacional e de 
abandono de política regional minimamente orientada para diminuição das desigualdades regionais, implicando uma nova associação, agora entre desintegração do mercado nacional e desindustrialização. Mesmo os setores específicos inseridos em trajetórias ascendentes e performances positivas, sejam industriais ou não, não estão vinculados a um movimento mais geral de unificação do mercado nacional, mas alavancados a dinâmicas internacionais cujas consequências regionais tendem a ser maior fragmentação.
Tal quadro foi e continua sendo agravado pela emergência e disseminação de práticas de guerra fiscal que emergiram entre nós diante do refluxo do abandono de políticas de corte regional capazes de coordenar espacialmente a dinâmica econômica. A retomada de políticas regionais entre 2003 e 2014 também não foi capaz de alterar tal situação. 0 Quadro 1 sintetiza a discussão até aqui.

No que toca especificamente a trajetória da economia paulista, assistiu-se a um grande e controverso debate a respeito dos rumos da

\section{Quadro 1 - Quadro sintético-comparativo}

\begin{tabular}{|c|c|c|}
\hline & $\begin{array}{l}\text { Dinâmica regional (integração vs. } \\
\text { desintegração do mercado nacional) }\end{array}$ & $\begin{array}{c}\text { Dinâmica do desenvolvimento } \\
\text { nacional (industrialização vs. } \\
\text { desindustrialização) }\end{array}$ \\
\hline $\begin{array}{l}\text { 1930-70 } \\
\text { Revolução de } 1930 \text { até "milagre" (I PND) }\end{array}$ & $\begin{array}{c}\text { Integração do mercado nacional } \\
+ \\
\text { Concentração da produção na RMSP }\end{array}$ & $\begin{array}{c}\text { Industrialização: construção de matriz } \\
\text { industrial de feições fordistas, integral } \\
\text { e integrado } \\
+ \\
\text { (1970) Inserção externa passiva; } \\
\text { financeirização do capitalismo }\end{array}$ \\
\hline $\begin{array}{l}1970-80 \\
\text { II PND }\end{array}$ & $\begin{array}{c}\text { Integração do mercado nacional } \\
+ \\
+ \\
\text { Desconcentração da produção da RMSP }\end{array}$ & $\begin{array}{c}\text { Industrialização: consolidação } \\
\text { da matriz industrial; depois, estagnação } \\
\text { e defasagem competitiva } \\
+ \\
\text { Endividamento externo, crise fiscal } \\
+ \\
\text { Aprofundamento da financeirização }\end{array}$ \\
\hline $\begin{array}{l}1999-2000 \\
\text { Reformas econômicas, abertura } \\
\text { e Plano Real. Remoção dos vetos } \\
\text { às políticas industrial e regional; } \\
\text { boom das commodities }\end{array}$ & $\begin{array}{c}\text { Fragmentação da nação } \\
+ \\
+ \\
\text { Refluxo da política regional; guerra fiscal } \\
+ \\
+ \\
\text { Ineficácia da política regional pós } 2003\end{array}$ & $\begin{array}{c}\text { Desindustrialização: reestruturação } \\
\text { produtiva, quebra de encadeamentos; } \\
\text { esvaziamento de elos; pressões } \\
\text { competitivas } \\
+ \\
\text { Contexto macroeconômico adverso } \\
\text { (tripé); ineficácia da política industrial } \\
\text { pós } 2003 \\
+ \\
\text { Inserção subordinada na economia } \\
\text { internacional; ápice da financeirização }\end{array}$ \\
\hline
\end{tabular}

Fonte: elaboração própria. 
RMSP: ${ }^{7}$ uma parte desse debate se dedicou à discussão a respeito da reversão da polarização da RMSP; outra parte à hipótese da desindustrialização da RMSP. Não cabe aqui reconstruir todo o debate, mas destacar alguns pontos e matizes do debate que nos ajudam na análise e caracterização da MMP.

1) Às formas primeiras e um tanto superficiais de caracterizar o fenômeno (desindustrialização da RMSP, à la Detroit), Azzoni (1986) contrapôs a tese da formação de um espaço econômico contíguo e integrado à dinâmica da RMSP, posteriormente batizado de Macrometrópole Paulista. Tal região corresponderia a um amplo território, com dinâmica econômica integrada à da RMSP e que receberia parte substantiva da indústria desmobilizada da capital paulista, bem como dos novos investimentos industriais direcionados a São Paulo. Nessa faixa, seria possível acessar os benefícios da proximidade à RMSP sem, contudo, ficar expostos aos seus maiores custos (deseconomias de aglomeração).

2) Abdal (2009) e Abdal et al. (2014), em diálogo direto com a tese da formação da MMP, trabalharam com a hipótese da hierarquia da desconcentração industrial da RMSP, segundo a qual somente os setores mais dependentes de custos e de menor intensidade de tecnologia apresentariam tendências centrífugas em relação à MMP e, sobretudo, à RMSP. Complementarmente, a capital paulista, município que efetivamente perdeu musculatura industrial nos últimos 40 anos, caminharia em vistas de consolidar capacidades produtivas nos setores de serviços especializados, que lidam mais intensamente com o conhecimento e que, em certo sentido, funcionam como importante fator aglomerativo para outros serviços, especializados ou não (na própria capital paulista) e para atividades industriais (nos entornos metro e macrometropolitano).

3) Mais importante do que discutir e disputar os grandes rótulos a respeito de São Paulo - seja se o município, a metrópole ou a macrometrópole permanece industrial ou não, se se tornou uma metrópole de serviços ou se se tornou uma cidade global (ou uma megacidade-região) -, é discutir e compreender quais atividades permanecem em São Paulo (município, metrópole e macrometrópole) (Torres-Freire, Abdal e Callil. 2012). Além disso, mas conectado a isso, enquanto principal polo produtivo nacional, a MMP sentiu, sente e sentirá de forma bastante intensa e particular os ciclos mais gerais da economia brasileira (Matteo, 2008).

4) Há a prevalência de importante fator inercial (path dependency) na trajetória de desenvolvimento regional brasileira, que afeta a MMP no sentido da manutenção da sobreconcentração da indústria de transformação no tempo. Isso porque os movimentos mais intensos de desconcentração regional da indústria no Brasil se fizeram a partir de novos investimentos (em detrimento da desmobilização de investimentos prévios), sendo os setores mais dinâmicos no passado recente e último suspiro de crescimento aqueles vinculados ao agronegócio, a recursos naturais e trabalho, ou seja, aqueles setores que já eram ou já estavam se tornando menos presentes na MMP (Abdal, 2015).

Deste ponto em diante, avançaremos na caracterização da MMP a partir da consideração de um conjunto selecionado de informações. As fontes são o Produto Interno Bruto dos Municípios (PIB-M) do Instituto Brasileiro de Geografia e Estatística (IBGE) e a Relação 
Anual de Informações Sociais (Rais) do Ministério do Trabalho e Emprego (MTE).

0 primeiro é integrante do sistema de contas nacionais do IBGE, sendo apresentado em valores correntes e com abertura para os três grandes setores: agropecuária, indústria (inclusive construção civil e extrativa) e serviços. Para tornar os valores comparáveis entre anos, optamos por trabalhar com a participação relativa ao invés dos valores absolutos. 0 segundo é um registro administrativo do emprego formal do Brasil, sendo usado para pesquisas de mercado de trabalho desde o final dos anos 1980. Nos últimos tempos passou, também, a ser utilizado por pesquisas da área dos estudos urbanos e regionais graças às suas enormes possibilidades de série histórica e desagregação setorial e geográfica, inclusive com estudos recentes ${ }^{8}$ apontando que os diferenciais regionais e/ou setoriais de produtividade e/ou formalização não colocam a evidência obtida a partir da manipulação da Rais em dissonância com as demais fontes de informação existentes.

Da perspectiva deste artigo, os principais benefícios decorrentes da incorporação da Rais é a possibilidade de diferenciar a indústria de transformação e os serviços em segmentos específicos, fugindo, portanto, da clausura que representa a agregação dos três grandes setores. Especificamente, mobilizamos a classificação da atividade segundo intensidade de tecnologia e desenvolvimento, consolidada por Abdal et al. (2016). A partir do estado da arte da discussão tipológica internacional, da manipulação de evidências da Pesquisa de Inovação (Pintec) do IBGE e de análise da Classificação Nacional de Atividade Econômica (Cnae), os autores agruparam as atividades manufatureiras e de serviços de acordo com a intensidade de tecnologia ou conhecimento que incorporam, deslocando a obsoleta oposição entre indústria e serviços para uma nova oposição entre atividades mais intensivas em tecnologia ou conhecimento contra atividades menos intensivas. A classificação é bastante adequada para a caracterização e análise de economias diversificadas e urbanizadas, como é o caso da MMP, pois possibilita diferenciação e identificação dos diferentes segmentos de atividades. São eles: (1) quatro ramos industriais, de alta, média-alta, média-baixa e baixa intensidade tecnológica; (2) seis ramos de serviços, os Serviços Intensivos em Conhecimento (SICs): tecnológicos, profissionais, financeiros, sociais e de mídia e cultura, e os demais serviços não intensivos em conhecimento; (3) atividades não classificadas, como comércio, administração pública, construção civil e agropecuária.

Como pode ser visto pelos dados do PIB-M (Tabela 1), a MMP mantém uma fatia bastante importante do PIB e do Valor Agregado (VA) industrial nacionais, de aproximadamente um quarto. Configura-se, assim, como uma das mais importantes aglomerações produtivas do País. Ao mesmo tempo, a tendência geral do período é de retração da participação da indústria na estrutura produtiva: 5,4 pontos percentuais para Brasil e 7,4 pontos percentuais para a MMP. É essa última evidência que remete àquele pano de fundo da desindustrialização.

Agora, tais tendências desindustrializantes são diferencialmente sentidas pelos distintos territórios da MMP. Tanto porque os ritmos de retração da indústria foram bastante diferentes, com MSP e Anel Metropolitano 


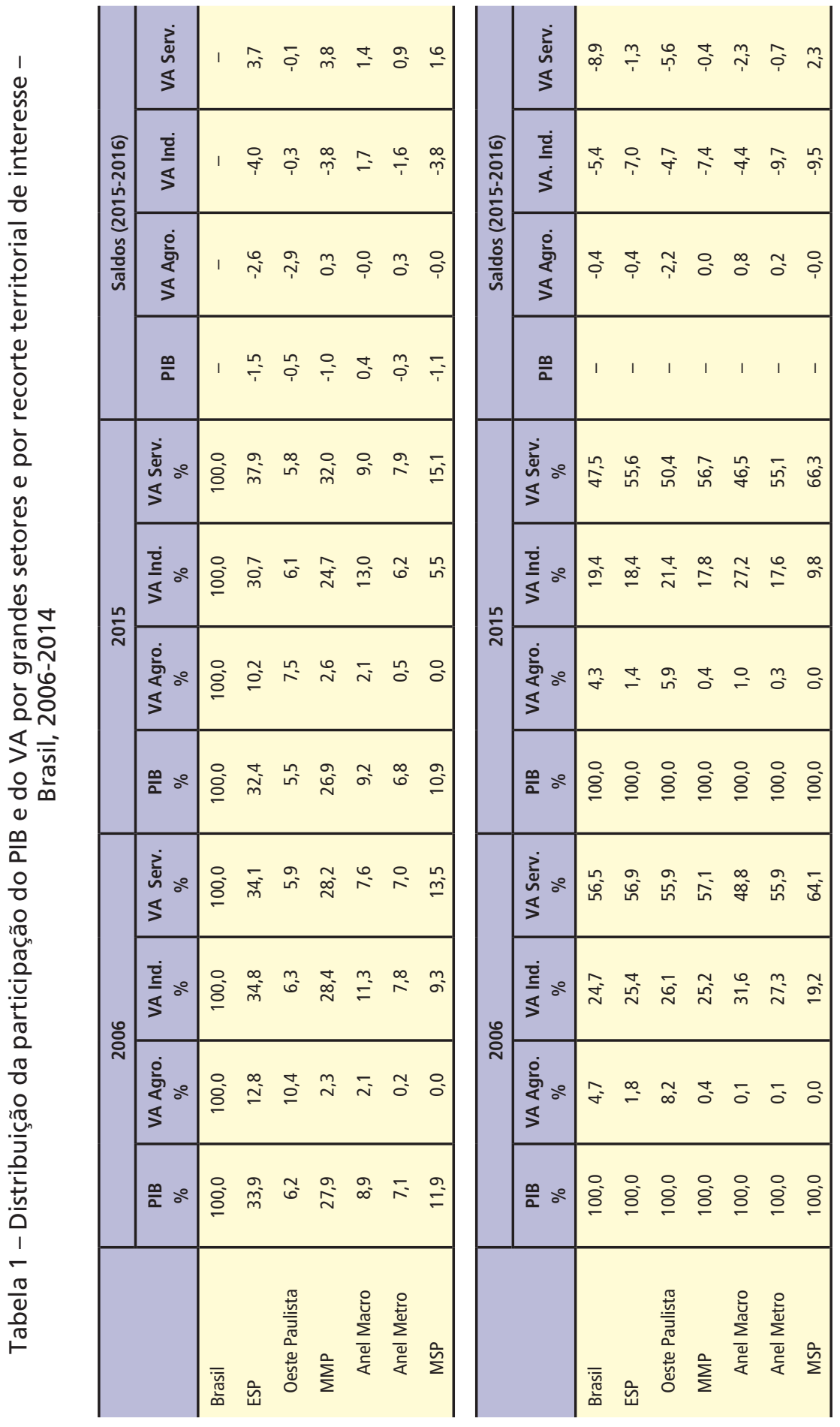

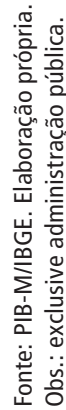


liderando tais retrações, quanto porque bases iniciais (2006) eram igualmente diferentes. 0 resultado líquido é que enquanto o MSP e o Anel Metropolitano lideram a perda de participação em suas respectivas estruturas produtivas e perdem participação no VA industrial brasileiro, o Anel Macrometropolitano observa a menor retração da indústria em sua estrutura produtiva e amplia a sua participação no VA industrial nacional (aproximadamente $13 \%$ em 2015, pouco mais que o dobro das participações relativas do MSP e do Anel Metropolitano).

Feita essa primeira aproximação, passamos, agora, para a discussão da evidência oriunda da Rais. Como dito anteriormente, a Rais possibilita a desagregação da indústria e dos serviços, segundo intensidade de tecnologia e conhecimento, permitindo, portanto, uma análise mais detalhada da MMP e de suas regiões. Importa notar, de agora em diante, como as dinâmicas espaciais desses diferentes segmentos são díspares entre si, denotando padrões locacionais bastante diversos. Para auxiliar nessa análise, além do número absoluto e relativo de empregos formais, calculamos, também, os Quocientes Locacionais (QLs). 0 QL é uma medida que, apesar de bastante simples, é muito usada em estudos de economia regional como indicativo de especialização produtiva.

Tabela 2 - PO formal por Classificação de atividade econômica segundo intensidade de tecnologia e conhecimento, MMP - 2006 e 2015

\begin{tabular}{l|c|c|c|c|c|c}
\hline & \multicolumn{3}{|c|}{2006} & \multicolumn{2}{c}{2015} & QL \\
\cline { 2 - 7 } & Abs. & $\%$ & QL & Abs. & $\%$ & 5,0 \\
\hline Ind. de alta & 509.425 & 6,3 & 1,08 & 538.802 & 5,04 \\
Ind. de média-alta & 196.356 & 2,4 & 1,14 & 211.710 & 2,0 & 1,08 \\
Ind. de média-baixa & 529.567 & 6,5 & 0,97 & 501.620 & 4,6 & 0,97 \\
Ind. de baixa & 443.531 & 5,4 & 0,76 & 458.122 & 4,2 & 0,71 \\
SIC-T & 75.363 & 0,9 & 1,15 & 123.857 & 1,1 & 1,15 \\
SIC-P & 236.918 & 2,9 & 1,17 & 442.348 & 4,1 & 0,13 \\
SIC-F & 229.215 & 2,8 & 1,08 & 302.421 & 2,8 & 1,09 \\
SIC-S & 419.297 & 5,2 & 0,97 & 650.881 & 6,0 & 0,99 \\
SIC-MC & 95.143 & 1,2 & 1,11 & 71.663 & 0,7 & 1,08 \\
Demais serviçOs & 2.321 .867 & 28,5 & 1,10 & 3.433 .894 & 31,8 & 1,09 \\
Comércio & 1.475 .832 & 18,1 & 0,98 & 2.072 .652 & 19,2 & 0,97 \\
Adm. pública & 1.210 .505 & 14,9 & 1,05 & 1.363 .251 & 12,6 & 1,02 \\
C. Civil & 309.280 & 3,8 & 1,05 & 556.833 & 5,1 & 1,04 \\
Ativ. primárias & 88.036 & 1,1 & 0,30 & 86.133 & 0,8 & 0,31 \\
\hline Total & 8.140 .335 & 100,0 & - & 10.814 .187 & 100,0 & - \\
\hline
\end{tabular}

Fonte: Rais/MTE. Elaboração própria. 
Para tanto, o QL compara a concentração de um setor em uma localidade específica com a concentração desse mesmo setor na economia de referência, bem como o tamanho da localidade específica com a economia de referência. ${ }^{9}$ QLs acima de 1,0 indicam sobreconcentração do setor vis-à-vis a economia de referência; QLs abaixo de 1,0 indicam subconcentração. Em geral, são tais QLs superiores a 1,0 que são tomados como indicativos de especialização produtiva.

A Tabela 2 traz a composição da estrutura produtiva da MMP. 0 conjunto da indústria de transformação, assim como o conjunto dos SICs, ocupa, no período, cerca de $15 \%$ dos empregados formais da MMP, configurando-se como o terceiro/quarto setor que mais emprega, atrás apenas de serviços e comércio. Em termos relacionais e tomando o estado de São Paulo como a economia de referência, a MMP esbanja especializações produtivas nas indústrias de mais alta intensidade de tecnologia e nos SICs, confirmando a percepção desse território como um espaço denso e diversificado, intensivo nos segmentos mais modernos e dinâmicos.

Contudo, internamente, a MMP é significativamente diferenciada, com divisão espacial de trabalho segundo a qual as áreas especializadas nos SICs não são as mesmas

Tabela 3 - Distribuição dos Quocientes Locacionais (QLs) da População Ocupada (PO) formal de segmentos selecionados, MMP e seus territórios (Anéis Macro e Metropolitanos e MSP) e Oeste Paulista 2006 e 2015

\begin{tabular}{|c|c|c|c|c|c|c|c|c|c|}
\hline & \multicolumn{4}{|c|}{ Indústria } & \multicolumn{5}{|c|}{ Serviços } \\
\hline & Alta & Média-A. & Média-B. & Baixa & SIC-T & SIC-P & SIC-F & SIC-S & SIC-MC \\
\hline & \multicolumn{4}{|c|}{ MMP } & \multicolumn{5}{|c|}{ MMP } \\
\hline 2006 & 1,08 & 1,14 & 0,97 & 0,76 & 1,15 & 1,17 & 1,08 & 0,97 & 1,11 \\
\hline \multirow[t]{2}{*}{2015} & 1,04 & 1,08 & 0,97 & 0,71 & 1,15 & 1,13 & 1,09 & 0,99 & 1,08 \\
\hline & \multicolumn{4}{|c|}{ Anel Macro } & \multicolumn{5}{|c|}{ Anel Macro } \\
\hline 2006 & 1,61 & 1,20 & 1,24 & 1,07 & 0,96 & 0,59 & 0,58 & 0,97 & 0,76 \\
\hline \multirow[t]{2}{*}{2015} & 1,71 & 1,28 & 1,40 & 1,05 & 1,01 & 0,69 & 0,55 & 0,90 & 0,63 \\
\hline & \multicolumn{4}{|c|}{ Anel Metro } & \multicolumn{5}{|c|}{ Anel Metro } \\
\hline 2006 & 1,60 & 1,89 & 1,61 & 0,75 & 1,37 & 1,19 & 0,84 & 0,66 & 1,17 \\
\hline \multirow[t]{2}{*}{2015} & 1,51 & 1,76 & 1,57 & 0,71 & 1,14 & 0,99 & 0,76 & 0,73 & 0,92 \\
\hline & \multicolumn{4}{|l|}{ MSP } & \multicolumn{5}{|c|}{ MSP } \\
\hline 2006 & 0,50 & 0,77 & 0,51 & 0,57 & 1,16 & 1,52 & 1,50 & 1,11 & 1,30 \\
\hline \multirow[t]{2}{*}{2015} & 0,40 & 0,64 & 0,41 & 0,49 & 1,26 & 1,49 & 1,60 & 1,17 & 1,44 \\
\hline & \multicolumn{4}{|c|}{ Oeste Paulista } & \multicolumn{5}{|c|}{ Oeste Paulista } \\
\hline 2006 & 0,70 & 0,46 & 1,11 & 1,90 & 0,45 & 0,36 & 0,70 & 1,12 & 0,60 \\
\hline 2015 & 0,84 & 0,70 & 1,12 & 2,10 & 0,43 & 0,51 & 0,65 & 1,03 & 0,71 \\
\hline
\end{tabular}


com especializações nos diferentes segmentos industriais (Tabela 3). Enquanto os Anéis Macrometropolitano e Metropolitano apresentam sobrerrepresentações consistentes de seus QLs nas indústrias de mais alta intensidade de tecnologia e, também, na indústria de média-baixa intensidade, o MSP concentra desproporcionalmente, com tendência à ampliação dessa concentração, os cinco segmentos de SICs. A título de comparação, o Oeste Paulista, por sua vez, concentra especializações nas indústrias de mais baixa tecnologia, sobretudo na de baixa intensidade, e sub-representações tanto nas indústrias de alta quanto nos SICs.

Embora não tenhamos feito aqui uma exposição exaustiva de evidências, destacamos que os dados apresentados são suficientes para sinalizar a adequação da interpretação, em termos gerais, da consolidação da MMP como amplo território nucleado a partir de São Paulo, portador de divisão espacial interna do trabalho. Segundo tal divisão, os Anéis Macrometropolitano e Metropolitano tendem à especialização nas indústrias de mais alta intensidade, enquanto o MSP tende à concentração nos serviços especializados, corroborando, simultaneamente, a hipótese da hierarquia da desconcentração industrial da RMSP e do MSP como buraco negro de SICs.

\section{Considerações finais: perspectivas para a Macrometrópole Paulista em um cenário de incertezas}

Ao longo do artigo, apresentamos e discutimos o processo de formação e consolidação do amplo território que ficou conhecido como MMP. Destacamos que esse processo ocorreu em um contexto mais amplo de (1) reestruturação e ampliação da competição inter-regional em nível global; (2) alteração da inserção da economia nacional na internacional, configurando o que caracterizamos como inserção subordinada; e (3) crescentes dificuldades para a indústria nacional, expressas nos diagnósticos de desindustrialização e especialização regressiva da pauta de exportações.

Ao mesmo tempo, destacamos que a consolidação da MMP conformou uma estrutura produtiva indústria-intensiva, com destacada representatividade na indústria nacional, e portadora de divisão espacial do trabalho própria. Se, por um lado, as atividades industriais de mais alta tecnologia tenderam à concentração nos Anéis Metro e Macrometropolitanos, os SICs tenderam a acentuar a sua concentração na capital paulista (enquanto a indústria de mais baixa intensidade tecnológica diminuiu a sua representação na MMP). Tais processos foram interpretados como hierarquia da desconcentração industrial, e São Paulo, capital, como buraco negro de SICs.

A MMP, enquanto região de estrutura produtiva densa, diversificada, indústria-intensiva e portadora de divisão espacial do trabalho, possui trajetória diretamente condicionada pelo contexto citado. Cenários futuros de manutenção da estagnação econômica ou de retomada de modelo de crescimento baseado em commodities e consumo das famílias tendem, de alguma forma, a manter os padrões de concentração industrial na MMP relativamente inalterados. Isso porque, como discutido ao longo do artigo, os movimentos mais intensos de desconcentração da 
produção foram feitos a partir de novos investimentos (e não a partir da desmobilização de investimentos já feitos). Alterações pontuais podem ocorrer, mas, sobretudo, devido a movimentos setoriais específicos associados a dinâmicas internacionais, como demandas dos mercados externos, ou de guerra fiscal levada a cabo por governos subnacionais.

No entanto, um cenário de recuperação do crescimento com retomada sustentada do dinamismo da indústria, por exemplo, a partir de políticas industriais ativas e eficazes, pode implicar dinamização do parque industrial da MMP. Caso desconectada de políticas regionais adequadas, tal dinamização pode levar, inclusive, a reforço da concentração industrial na MMP. Em que pese o argumento subjacente do artigo, de que a retomada do dinamismo industrial é um objetivo político-econômico a ser perseguido, o reforço da concentração produtiva nas áreas já industrializadas não é, necessariamente, um ponto positivo.

Não somos exatamente saudosistas de um passado cuja sobrerrepresentação da indústria na RMSP sinalizava alguma suposta liderança ou grandeza. Ao contrário, acreditamos e defendemos que a construção de um País menos desigual passa, também, por uma menor desigualdade produtivo-regional. Por isso, o hipotético cenário desejável de reversão da desindustrialização implica, também, a retomada da capacidade do Estado brasileiro em ancorar e acomodar territorialmente o desenvolvimento industrial, de modo a não repetir erros do passado associados à hiperconcentração da produção industrial em territórios bastante restritos.

\section{[I] https://orcid.org/ 0000-0003-3577-1238}

Fundação Getúlio Vargas, Escola de Administração de Empresas de São Paulo. São Paulo, SP/Brasil. Centro Brasileiro de Análise e Planejamento. São Paulo,SP/Brasil.

Observatório das Metrópoles, núcleo São Paulo. São Paulo, SP/Brasil.

alexandre.abdal@fgv.br

\section{[II] https://orcid.org/0000-0002-3812-8806}

Pontifícia Universidade Católica de São Paulo, Programa de Pós-Graduação em Economia Urbana e Gestão Pública. São Paulo, SP/Brasil.

caio.macedo@direitosbc.br

\section{[III] https://orcid.org/ 0000-0003-0701-8986}

Universidade Federal do ABC, Centro de Engenharia, Modelagem e Ciências Sociais Aplicadas, Bacharelados de Ciências Econômicas e de Ciências Humanas. Santo André, SP/Brasil.

Observatório das Metrópoles, núcleo São Paulo. São Paulo, SP/Brasil. gabriel.rossini@ufabc.edu.br

\section{[IV] https://orcid.org/0000-0001-7631-6050}

Pontifícia Universidade Católica de São Paulo, Faculdade de Economia, Administração, Contabilidade e Ciências Atuariais, Departamento de Economia. São Paulo, SP/Brasil.

ricardogaspar@pucsp.br 


\section{Notas}

$\left(^{*}\right)$ Os autores deste artigo estão ordenados por ordem alfabética, não havendo, portanto, "primeiro autor". As reflexões iniciais e as considerações que posteriormente configuraram o artigo ocorreram no âmbito da atuação dos autores, seja como coordenadores, professores ou aluno, do curso de especialização Economia Urbana e Gestão Pública da PUC-SP. Atualmente, o artigo está inserido no bojo das atividades do Observatório das Metrópoles, Núcleo São Paulo.

(1) Segundo João Manuel Cardoso de Mello, "há industrialização, porque a dinâmica da acumulação passa a se assentar na expansão industrial, ou melhor, porque existe um movimento endógeno de acumulação de capital em que se reproduzem, conjuntamente, a força de trabalho e parte crescente do capital constante industriais; mas a industrialização se encontra restringida, porque as bases técnicas e financeiras da acumulação não são suficientes para que se implante, num golpe, o núcleo fundamental da indústria de bens de produção, que permitiria à capacidade produtiva crescer adiante da demanda, autodeterminando o processo de desenvolvimento industrial" (Mello, 1982, p. 110). Ver também: Cano (2015).

(2) Para uma avaliação divergente acerca da ocorrência ou não de desindustrialização da economia brasileira, ver Nassif (2008).

(3) Para uma análise da Política Industrial, Tecnológica e de Comércio Exterior (PITCE), ver Cano e Silva (2010).

(4) Entre os muitos autores possíveis, citamos apenas um: Paulani (2008).

(5) A participação da indústria de transformação no PIB no Brasil caiu de 33\%, no ano de 1980, para 14,6\% em 2011 (Cano, 2012). Além disso, segundo dados do Bacen, a participação da indústria de transformação no IED total que girava em torno de $75 \%$ nos anos de 1980 cai para cerca de $60 \%$ nos anos 1990 e flutua entre $30 \%$ e $40 \%$ a partir de 2001, chegando, em 2017, com pouco mais de 33\% (dados disponíveis em: https://www.bcb.gov.br/htms/Infecon/SeriehistFluxolnvDir.asp; acesso em: 29 maio 2018).

(6) Para uma argumentação diferente, que vê o fenômeno que interpretamos como uma mera correção de rumo de uma estrutura produtiva excessivamente industrializada ("doença soviética"), ver Bonelli et al. (2013).

(7) Ver, por exemplo, Tinoco (2001), Comin e Amitrano (2003) e Abdal (2009).

(8) Referimo-nos especificamente a Pacheco (1999) e Sabóia (2001 e 2013).

(9) O cálculo do QL (e de outras medidas locacionais) pode ser encontrado em Haddad et al. (1989). 


\section{Referências}

ABDAL, A. (2009). São Paulo, desenvolvimento e espaço: a formação da macrometrópole paulista. São Paulo, Papagaio.

(2015). Sobre regiões e desenvolvimento: os processos de desenvolvimento regional brasileiro no período 1999-2010. Tese de Doutorado. São Paul, Universidade de São Paulo.

ABDAL, A. et al. (2014). A geografia da atividade econômica no Estado de São Paulo: identificando territórios segundo a intensidade de tecnologia e conhecimento. Revista Estudos de Sociologia, v. 19, n. 37. Araraquara, Unesp.

(2016). Rethinking sectorial typologies: a classification of activity according to knowledge and technology intensity. RAl, v. 13, n. 4, pp. 232-241. São Paulo, FEA/USP.

ARRIGHI, G. (2008). Adam Smith em Pequim: origens e fundamentos do século XXI. São Paulo, Boitempo.

AZZONI, C. R. (1986). Indústria e reversão da polarização no Brasil. São Paulo, IPE-USP.

BARBOSA, A. (2011). "China e América Latina na nova divisão internacional do trabalho". In: FERREIRA, R. P. et al. (orgs.). A China na nova configuração global: impactos políticos e econômicos. Brasília, Ipea.

BIANCARELLI, A.; ROSA, R. e VERGNHANINI, R. (2018). "O setor externo no governo Dilma e seu papel na crise". In: CARNEIRO, R.; BALTAR, P. e SARTI, F. (orgs.). Para além da política econômica. São Paulo, Unesp Digital.

BIELSCHOWSKY, R. (1998). Investimentos na indústria brasileira, 1995/97. Características e determinantes. Rio de Janeiro, CNI.

BONELLI, R. (2005). "O que causou o crescimento econômico no Brasil”. In: GIAMBIAGI, F. et al. (orgs.). Economia brasileira contemporânea (1945-2004). Rio de Janeiro, Campus.

BONELLI, R. e GONÇALVES, R. R. (1998). Para onde vai a estrutura industrial brasileira? Texto para discussão IPEA, n. 540. Rio de Janeiro.

BONELLI, R. et al. (2013). "Desindustrialização no Brasil: fatos e interpretação". In: BACHA, E. e BOLLE, M. (orgs.). O futuro da indústria no Brasil: desindustrialização em debate. Rio de Janeiro, Civilização Brasileira.

BRESSER-PEREIRA, L. C. (2008). The Dutch disease and its neutralization: a Ricardian approach. Revista de Economia Política, v. 28, n. 1, pp. 47-71.

(2012). A taxa de câmbio no centro da teoria do desenvolvimento. Estudos Avançados, v. 26, n. 75.

BRENNER, N. (2004). New State Spaces: urban governance and the rescaling of statehood. Oxford, University Press.

CANO, W. (1998). "Concentração e desconcentração econômica regional no Brasil: 1970-1995". In: CANO, W. Desequilíbrios regionais e concentração industrial no Brasil: 1930-1970 e 1970-1995. Campinas, IE-Unicamp.

(2012). Texto para discussão IE/Unicamp, n. 200. Campinas. 
CANO, W. (2015). Crise e industrialização no Brasil entre 1929 e 1954: a reconstrução do Estado Nacional e a política nacional de desenvolvimento. Revista de Economia Política. v .35 n.3. São Paulo.

CANO, W. e SILVA, A. L. (2010). Política industrial do governo Lula. Texto para Discussão. IE/UNICAMP n. 181.

CARVALHO, L. e KUPFER, D. (2008). A transição estrutural da indústria brasileira: uma análise dos fatores explicativos pela ótica da demanda. In: XXXVI ENCONTRO NACIONAL DE ECONOMIA DA ANPEC. Anais. Salvador, Bahia.

CHESNAIS, F. (2016). Finance capital today: corporations and banks in the lasting global slump. Leiden, Brill, Historical Materialism Book Series.

COMIN, A. e AMITRANO, C. (2003). Economia e emprego: a trajetória recente da região metropolitana de São Paulo. Novos Estudos Cebrap, n. 66.

COMIN, A. et al. (orgs.) (2012). Metamorfoses paulistanas: atlas geoeconômico da cidade. São Paulo, SMDU/Cebrap/Unesp/Imprensa Oficial.

DINIZ, C. C. (1993). Desenvolvimento poligonal no Brasil: nem desconcentração, nem contínua polarização. Nova Economia. Belo Horizonte, v. 3, n. 1.

DINIZ, C. C. e DINIZ, B. C. (2004). “A região metropolitana de São Paulo: reestruturação, re-espacialização e novas funções". In: Caminhos para o Centro: estratégias de desenvolvimento para a região central de São Paulo. São Paulo, Emurb/Cebrap/CEM.

FERRAZ, J. C. et al. (2004). Competitividad industrial en Brasil: 10 años después da la liberalización. Revista de la CEPAL, n. 82.

FURTADO, C. (2009[1950]). Formação econômica do Brasil. São Paulo, Companhia das Letras.

GASPAR, R. C. (2009). A cidade na geografia econômica global: um panorama crítico da urbanização contemporânea. São Paulo, Publisher Brasil.

(2011). A economia política da urbanização contemporânea. Cadernos Metrópole, v. 13, n. 25. São Paulo, Educ.

GUTTMANN, R. (2008). Uma introdução ao capitalismo dirigido pelas finanças. Novos estudos Cebrap, n. 82.

HADDAD, P. R. et al. (orgs). (1989). Economia regional: teorias e métodos de análise. Fortaleza, Banco do Nordeste do Brasil.

IBGE (2008). Região de influência das cidades: 2007. Rio de Janeiro, IBGE. Disponível em: www.ibge. gov.br/home/geociencias/geografia/regic.shtm. Acesso em: 5 set 2018.

KUPFER, D. (2003). Política Industrial. Econômica: revista da Pós-Graduação em Economia da UFF. Rio de Janeiro, v. 5, n. 2, pp. 281-298.

LENCIONI, S. (2011). A metamorfose de São Paulo: o anúncio de um novo mundo de aglomerações difusas. Revista Paranaense de Desenvolvimento, n. 120, pp. 133-148.

LOPES, F. L. (1985). Inflação inercial, hiperinflação e desinflação: notas e conjecturas. Revista de Economia Política, v. 5, n. 2, pp. 135-151.

MARCONI, N. e ROCHA, M. (2011). Desindustrialização precoce e sobrevalorização da taxa de câmbio. Texto para discussão, Ipea TD 1681. Rio de Janeiro, Ipea. 
MARKUSEN, A. e SCHROCK, G. (2006). The distinctive city: divergent patterns in growth, hierarchy and specialization. Urban Studies, n. 43, n. 8 , pp. 1301-1323.

MARQUETTI, A. (2002). Progresso técnico, distribuição e crescimento na economia brasileira: 19551998. Estudos Econômicos, v. 32, n. 1, pp. 103-124.

MATTEO, M. (2008). Além da metrópole terciária. Tese de Doutorado. Campinas, Universidade Estadual de Campinas.

MATTOS, C. A. de (2008). “Globalización, negocios inmobiliarios y mercantilización del desarrollo urbano". In: MONTÚFAR, M. C. (coord.). Lo urbano en su complejidad: una lectura desde América Latina. Quito, Flacso Ecuador e Ministerio de Cultura del Ecuador.

MELLO, J. M. C. de. (1982). O capitalismo tardio. São Paulo, Brasiliense.

MORAIS, L. e SAAD FILHO, A. (2011). Da economia política à política econômica: o novodesenvolvimentismo e o governo Lula. Revista de Economia Política, v. 31, n. 4, pp. 507-527.

NASSIF, A. (2008). Há evidência de desindustrialização no Brasil? Revista de Economia Política, v. 28, n. 1, pp. 72-96.

OBSERVATÓRIO DAS METRÓPOLES (2009). Hierarquização e identificação dos espaços urbanos. Rio de Janeiro, Letra Capital e Observatório das Metrópoles.

OREIRO, J. L. e FEIJÓ, C. A. (2010). Desindustrialização: conceituação, causas, efeitos e o caso brasileiro. Revista de Economia Política, v. 30, n. 2, pp. 219-232.

PACHECO, C. A. (1998). Fragmentação da nação. Campinas, IE/Unicamp.

(1999). Novos padrões de localização industrial? Tendências recentes dos indicadores da produção e do desenvolvimento industrial. Ipea - Texto para discussão n. 633. Brasília, Ipea.

PAULANI, L. (2008). Brasil Delivery. São Paulo, Boitempo.

(2012). A inserção da economia brasileira no cenário mundial: uma reflexão sobre a situação atual à luz da história. Boletim de Economia e Política Internacional-Ipea, v. 3, n. 10, pp. 89-102.

SCOTT, A. J. (2012). A world in emergence: cities and regions in the 21st century. Chelterham/UK, Edward Elgar Publishing.

SABÓIA, J. (2001). Descentralização industrial no Brasil na década de 1990: um processo dinâmico e diferenciado regionalmente. Nova Economia, v. 11, n. 2.

(2013). A continuidade do processo de desconcentração regional da indústria brasileira nos anos 2000. Nova Economia, v. 23, n. 2, pp.219-277.

SEADE e EMPLASA (2011). Estudo da morfologia e da hierarquia funcional da rede urbana paulista e regionalização do Estado de São Paulo. São Paulo, Fundação Seade.

TAVARES, M. C. et al. (2007). Centro Internacional Celso Furtado de Políticas para o Desenvolvimento. Memórias do desenvolvimento - Ano 1, n.1. Rio de Janeiro.

TAVARES, M. C. (1963). Da substituição de importações ao capitalismo financeiro. Rio de Janeiro, Zahar.

(1999). Destruição não criadora. Rio de Janeiro, Record.

TINOCO, A. de C. (2001). Integração ou fragmentação? O impasse gerado pelo fetichismo da desconcentração. Espaço \& Debates, v. 41, pp. 46-65. 
TORRES-FREIRE, C.; ABDAL, A. e CALLIL, V. (2012). Conhecimento e tecnologia: base para o desenvolvimento econômico do Estado de São Paulo. Relatório de Pesquisa, desenvolvido no âmbito do projeto: Desenvolvimento e território: subsídios para um planejamento regional do estado de São Paulo. Cebrap/Emplasa.

TREGENNA, F. (2009). Characterizing deindustrialization: an analysis of changes in manufacturing employment and output internationally. Cambridge Journal of Economics, v. 33, n. 3.

(2011). Manufacturing productivity, deindustrialization and reindustrialization. United Nations University (UNU) - World Institute for Development Economics Research (WIDER). Working Paper, n. 57, sept.

Texto recebido em 12/jul/2018

Texto aprovado em 21/set/2018 